\title{
Depressive symptoms in caregivers of patients with dementia: demographic variables and burden
}

This article was published in the following Dove Press journal:

Clinical Interventions in Aging

I July 2015

Number of times this article has been viewed

\section{Pasquale De Fazio' \\ Paola Ciambrone' \\ Gregorio Cerminara' \\ Elvira Barbuto' \\ Antonella Bruni' \\ Patrizia Gentile' \\ Amalia Talarico ${ }^{2}$ \\ Roberto Lacava ${ }^{2}$ \\ Pietro Gareri ${ }^{2}$ \\ Cristina Segura-García' \\ 'Psychiatric Unit, Department of Health Sciences, University Magna Graecia, Catanzaro, Italy; ${ }^{2}$ Unit for the Elderly, ASP Catanzaro, Catanzaro, Italy}

Correspondence: Pasquale De Fazio Psychiatric Unit, Department of Health Sciences, University Magna Graecia, Viale Europa, Catanzaro 88I00, Italy Tel +390961712408 Fax +390961 712393 Email defazio@unicz.it
Objective: Individuals suffering from dementia are affected by a progressive and significant global deterioration and, consequently, might require longer assistance in the advanced stage of the illness. The illness is a great burden on the person who takes care of a patient, namely, the caregiver. This study aims to analyze the presence and relationship of specific sociodemographic variables, subjective burden, and depressive symptoms among caregivers of patients with dementia.

Methods: The participants of this study were caregivers at a health care unit for the elderly in southern Italy. An evaluation of the burden of patients with dementia on caregivers was carried out using the Caregiver Burden Inventory (CBI) and depressive symptoms using the Self-Rating Depression Scale (SDS).

Results: A total of 150 caregivers completed the study. In all, 83 (55\%) caregivers showed a total CBI score $\geq 36$, of whom $70 \%$ showed pathological depression scores in SDS. According to SDS, 28 (19\%) caregivers showed a total CBI score from 24 to 36 , of whom $32 \%$ were depressed. Depression was present in $5 \%$ of the caregivers whose CBI score was $<24$. Hence, an association between burden and depression was evident $\left(\chi^{2}=47.446, P<0.001\right)$. A multiple linear regression analysis showed that depression (adjusted $R^{2}=0.622, F=50.123, P<0.001$ ) was associated with higher physical $(\beta=0.666, P=0.001)$ and developmental $(\beta=0.712, P<0.001)$ burdens, lower socioeconomic status ( $\beta=-4.282 ; P=0.002)$, higher level of urbanicity $(\beta=3.070$; $P=0.012)$, and advanced age $(\beta=2.132 ; P=0.08)$.

Conclusion: Our study confirms the presence of depressive symptoms in a large number of caregivers with high burden. Nevertheless, this study demonstrates that depressive symptoms are mainly associated with sociodemographic variables and, to a lesser degree, physical and developmental burdens.

Keywords: caregiver, dementia, depression, developmental burden, elderly, physical burden

\section{Introduction}

The average human life expectancy has been progressively prolonged over the last few decades, with a consequent rise in the prevalence of chronic degenerative disorders, one of which is dementia. It has been estimated that, in 2010 , there were 35.6 million patients suffering from some form of dementia, worldwide. International epidemiological studies foresee that this number is destined to double every 20 years. Therefore, it is expected to reach 65.7 million in 2030 and 115.4 million by $2050 .{ }^{1}$

Individuals suffering from dementia are affected by a progressive and significant global deterioration and, consequently, might require longer assistance in the advanced stage of the illness. ${ }^{2,3}$ The person who takes care of a patient with dementia is known as a caregiver; in most cases, the caregiver is a family member. ${ }^{4}$

Assisting a person affected by cognitive disorders can drain the emotional resources of any individual so much that the caregiver is often defined as "the hidden patient" 
due to the not unlikely possibility of developing mental and physical symptoms. In fact, caregivers end up dedicating less time to their own needs and to other family and professional roles, thus neglecting their own personal health and social life. ${ }^{5,6}$

Alzheimer's disease (AD) and other related dementias are public health priorities in the European Union because of their prevalence, cost, and profound impact on society. Nineteen participating countries of the European Union created the Joint Action Alzheimer Cooperative Valuation in Europe (ALCOVE) to share knowledge about dementia to preserve the health, quality of life, autonomy, and dignity of people living with dementia and their carers. ${ }^{7}$

The impact of the illness on the caregiver is defined as burden, a term that expresses the comprehensive effect on the caregiver's global needs in the course of looking after the patient (ie, physical, psychological, and social).

Numerous studies have noted that the problems that mainly affect the caregiver range from simple physical fatigue, problems with the family and at work, feelings of incapacity and inadequacy, sleeping difficulties, depression, and anxiety. ${ }^{8,9}$ In other cases, the depressed caregiver can be affected by the onset of more complex pathologies, such as arterial hypertension and gastrointestinal pathologies. ${ }^{10}$ Others have reported that caregiving per se does not always lead to mental or physical impairment. ${ }^{11}$

This study aims to analyze the presence and relationship between specific sociodemographic variables, the subjective burden, and depressive symptoms among caregivers of patients with dementia. We hypothesize that high levels of burden may predict more severe depressive symptoms.

\section{Methods}

\section{Participants}

A total of 150 caregivers of patients under treatment at the Unità Operativa Tutela Anziani in Catanzaro (southern Italy) were consecutively recruited for this study. Unità Operativa Tutela Anziani is a health care unit for the elderly, specialized in the diagnosis and care of dementia. Inclusion criteria of our study were spouses, next of kin, and other close family members of patients who scored $\geq 2$ on the Clinical Dementia Rating scale. ${ }^{12}$

\section{Procedures}

Physicians with adequate and specific training in this field of research interviewed the participants. Data were collected for the following variables: demographics (sex, age, kinship to the patient, civil state, education, socioeconomic level [average annual income]), occupation, perceived state of health, level of urbanity (high densely populated area: $>500$ inhabitants $/ \mathrm{km}^{2}$ or total population $>50,000$ inhabitants; middle densely populated area: $>100$ inhabitants $/ \mathrm{km}^{2}$ or total population $>50,000$ inhabitants; low densely populated area: $<100$ inhabitants $/ \mathrm{km}^{2}$ or total population $>50,000$ ), cohabitation with the patient, attendance in family support groups, type and entity of the subjective burden and, therefore, the stress in relation to assisting the patient, and the presence of contingent depressive symptoms. The interviews with the caregivers were conducted in a separate room during the time when the patients were visited by their neurologists.

The evaluation of the caregivers' burden was assessed by means of the Caregiver Burden Inventory (CBI). ${ }^{13,14}$ It is an easy-to-administer tool to evaluate the burden of caregivers of patients with $\mathrm{AD}$ and correlated dementia in multifaceted dimensions: objective, psychological, physical, social, and emotional. This self-report tool must be compiled by the main caregiver, who is asked to identify the answer most closely matching his or her own conditions or personal impressions. The objective burden, or time-dependence, describes the burden associated with time restriction for the caregiver and relates to time required for patient assistance (items 1-5); the developmental burden (items 6-10) describes the caregiver's perception of isolation compared with his peers; the physical burden (items 11-14) describes the feelings of chronic fatigue and somatic health problems; the social burden (items 15-19) explains role conflicts; and the emotional burden (items 20-24) describes feelings toward the patient's behavior.

Five items account for each dimension, except for the physical burden, which is composed of four items, in a Likert-type scale of $0-4$. The total score ranges from 0 to 100; scores for each dimension increase proportionally with the severity of the burden perceived by the caregiver. Profiles are used to build ad hoc psychosocial interventions. ${ }^{15}$ A total CBI score between 24 and 36 indicates a need to seek some form of respite care, whereas a total $\mathrm{CBI}$ score $>36$ indicates a risk of burnout. Equal total scores may relay very different profiles of burden, depending on the score of each dimension. Cronbach's alpha in the present study was 0.914 .

Depressive symptoms were assessed using the SelfRating Depression Scale (SDS). ${ }^{16}$ This well-validated scale consists of 20 Likert-type items (0-4). It is composed of 20 items investigating concomitant psychological and physiological depressive symptoms (depressed mood, morning symptoms, crying, insomnia, diminished appetite, weight 
loss, sexual interest, constipation, palpitations, fatigue, clouded reasoning, difficulty with completing tasks, difficulty with decision making, restlessness, lack of hope, irritability, diminished self-esteem, life satisfaction, suicidal ideation, and anhedonia). Answers are rated with a four-point Likert scale: rarely, sometimes, often, and almost always. The total score allows to evaluate the intensity of depressive symptoms in the last week.

Total SDS scores in the ranges of 20-49, 50-59, 60-69, or $>70$ indicate normal mood, mild depression, moderate, and severe depression, respectively.

All the participants were given full information about the goals and the methods of the research; they were also informed that their participation was voluntary and anonymous. All the participants signed a written informed consent before recruitment into the study. The study, which was conducted over a period of 6 months, from June 2010 until November 2010, was approved by the local Committee for Ethics and Research.

\section{Statistical design}

Data were analyzed using SPSS 21.0 and presented as means, standard deviations, frequencies, and percentages $(\%)$. Univariate analyses included $t$-test and chi-square test for the comparison of numerical and categorical variables, respectively. The level of statistical significance was set at $P<0.05$. Cohen's effect sizes were calculated for all significant findings; values (negative or positive) of $0.2,0.6,1.2$, and $>1.2$ indicated trivial, small, moderate, and large effect sizes, respectively. ${ }^{17}$

Multivariate analysis consisted of forward, stepwise multiple linear regression techniques to assess possible associations between depression (dependent variable) and CBI dimensions and sociodemographic characteristics as independent variables. Alpha level for variables entering the logistic regression model was set at 0.2 , and alpha level for removal was set at 0.4 .

\section{Results}

Table 1 shows the sociodemographic characteristics of the sample and the results of CBI and SDS by sex. Approximately $79 \%(n=118)$ of the caregivers were women; most of them were older than 50 years and children of the patients. Most of the caregivers were married and completed education at secondary school.

According to the interviews, $21 \%(n=31)$ of the caregivers perceived their health condition as insufficient, $40 \%(\mathrm{n}=61)$ as moderate, $36 \%(n=54)$ as good, and only $3 \%(n=4)$ as very good. The women described their own heath condition as worse than the men's condition $\left(\chi^{2}=7.806, P=0.05\right)$. Ninety-three percent reside in cities with more than 10,000 inhabitants, and $53 \%(\mathrm{n}=80)$ live with the patients they assist (these data are not in the tables).

The interviews revealed important changes in sleep, mastery, and stress that occurred in the short-term among 73 caregivers, but it was not possible to measure these changes through precise and appropriate scientific measures.

With regard to $\mathrm{CBI}, 83(52 \%)$ caregivers showed a total score $\geq 36$ (indicating high stress related to burden), of whom $72 \%$ showed pathological depression scores in SDS. Furthermore, only $1 / 3$ of the caregivers who scored between 24 and 36 on the CBI scale and $7 \%(n=3)$ who scored $<24$ had results indicating mild depression. Hence, an association between burden and depression was evident $\left(\chi^{2}=50.545, P<0.001\right)$. CBI scores were similar in men and women $(t=-1.031, d f=148, P=0.304)$.

No significant differences were evident between men and women $(t=-1.112, d f=148, P=0.268)$, who showed average depression scores within the range of normal (normal range: 54\%, mildly depressed: 33\%, moderately depressed: $13 \%$ ).

The results of multiple linear regression analyses are illustrated in Table 2. Depression results (adjusted $R^{2}=0.622$, $F=50.123, P<0.001)$ were associated with higher physical $(\beta=0.666, P=0.001)$ and developmental $(\beta=0.712, P<0.001)$ burdens, lower socioeconomic status ( $\beta=-4.282, P=0.002)$, higher level of urbanicity $(\beta=3.070, P=0.012)$, and advanced age $(\beta=2.132, P=0.08)$.

\section{Discussion}

Present results give a personal and social portrait of caregivers of patients who suffer from dementia in southern Italy and confirm the main results of literature in the field. There are differing opinions regarding the effects caused by the burden of dementia on caregivers. The positive value of caregiving has been emphasized in a large sample of carers taken from six European countries, as evaluated through the Carers of Older People in Europe (COPE) Index. ${ }^{18}$

\section{Sociodemographic characteristics}

In our sample, women are overrepresented among caregivers, demonstrating that females are the principal figures of support in families. ${ }^{19-21}$

According to Fauth and Gibbons, ${ }^{22}$ the average age of caregivers assisting patients with dementia is over 50 years, which is true for the $62 \%$ of the participants of our sample. In Italy, family is the principal source of care and assistance for 
Table I Characteristics of the sample and CBI and SDS scores

\begin{tabular}{|c|c|c|c|c|c|c|}
\hline & \multicolumn{2}{|c|}{ Male $(n=32)$} & \multicolumn{2}{|c|}{ Female $(n=\mid 18)$} & \multirow[t]{2}{*}{ Comparison } & $P$-value \\
\hline \multicolumn{6}{|l|}{ Age $^{a}$ (years) } & \\
\hline$<30$ & 1 & (3) & 2 & (2) & \multirow[t]{3}{*}{$\chi^{2}=3.33$} & \multirow[t]{3}{*}{0.189} \\
\hline $31-49$ & 7 & $(22)$ & 46 & (39) & & \\
\hline$>50$ & 24 & $(75)$ & 70 & (59) & & \\
\hline \multicolumn{7}{|l|}{ Type of relation ${ }^{\mathrm{a}}$} \\
\hline Spouse & 9 & $(28)$ & 20 & $(17)$ & \multirow{6}{*}{$\chi^{2}=8.156$} & \multirow[t]{6}{*}{0.148} \\
\hline Parent & 0 & $(0)$ & 3 & (3) & & \\
\hline Son/daughter & 19 & (59) & 70 & (59) & & \\
\hline Brother & 1 & (3) & 0 & $(0)$ & & \\
\hline Sister & 0 & $(0)$ & 2 & $(2)$ & & \\
\hline Other & 3 & (9) & 23 & (20) & & \\
\hline \multicolumn{7}{|l|}{ Civil status $^{\mathrm{a}}$} \\
\hline Single & 2 & $(6)$ & 9 & (8) & \multirow{4}{*}{$\chi^{2}=3.061$} & \multirow[t]{4}{*}{0.382} \\
\hline Married & 30 & $(94)$ & 99 & $(84)$ & & \\
\hline Widowed & 0 & $(0)$ & 8 & (7) & & \\
\hline Separated & 0 & (0) & 2 & (2) & & \\
\hline \multicolumn{7}{|l|}{ Number of children ${ }^{a}$} \\
\hline 0 & 5 & $(16)$ & 30 & $(25)$ & \multirow{8}{*}{$\chi^{2}=4.65$} & \multirow[t]{8}{*}{0.703} \\
\hline I & 2 & (6) & 5 & (4) & & \\
\hline 2 & 15 & $(47)$ & 47 & $(40)$ & & \\
\hline 3 & 7 & $(22)$ & 19 & (16) & & \\
\hline 4 & 2 & (6) & 11 & (9) & & \\
\hline 5 & 0 & (0) & 4 & (3) & & \\
\hline 6 & 0 & $(0)$ & 1 & (I) & & \\
\hline 7 & I & (3) & 1 & (I) & & \\
\hline \multicolumn{7}{|l|}{ Education $^{\mathrm{a}}$} \\
\hline Primary school & 8 & $(25)$ & 28 & $(24)$ & \multirow{4}{*}{$\chi^{2}=1.736$} & \multirow[t]{4}{*}{0.629} \\
\hline Lower secondary school & 10 & $(31)$ & 25 & $(2 I)$ & & \\
\hline Higher secondary school & 11 & (34) & 52 & (44) & & \\
\hline Degree & 3 & (9) & 13 & (II) & & \\
\hline \multicolumn{7}{|l|}{ Socioeconomic status ${ }^{\mathrm{a}}$} \\
\hline Low & 7 & $(22)$ & 34 & $(29)$ & \multirow[t]{3}{*}{$\chi^{2}=1.249$} & \multirow[t]{3}{*}{0.536} \\
\hline Middle & 25 & $(78)$ & 82 & $(70)$ & & \\
\hline High & 0 & (0) & 2 & (2) & & \\
\hline \multicolumn{7}{|l|}{$\left.\mathrm{CB}\right|^{\mathrm{b}}$} \\
\hline Objective burden & 12.69 & 4.987 & 13.47 & 4.942 & $t=-0.798$ & 0.426 \\
\hline Developmental burden & 8.66 & 5.711 & 9.67 & 6.342 & $t=-0.818$ & 0.415 \\
\hline Physical burden & 8.48 & 6.154 & 10.18 & 5.540 & $t=-01.506$ & 0.134 \\
\hline Social burden & 3.56 & 4.181 & 3.59 & 3.708 & $t=-0.040$ & 0.968 \\
\hline Emotional burden & 2.72 & 3.103 & 2.93 & 3.107 & $t=-0.345$ & 0.731 \\
\hline Total score & 36.10 & $|8.66|$ & 39.85 & 18.126 & $t=-01.031$ & 0.304 \\
\hline \multicolumn{7}{|l|}{ SDS } \\
\hline Total score & 43.16 & 14.357 & 45.78 & 11.073 & $t=-01.112$ & 0.268 \\
\hline
\end{tabular}

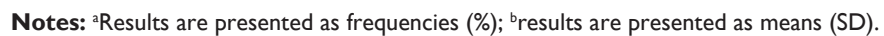

Abbreviations: CBI, Caregiver Burden Inventory; SDS, Self-Rating Depression Scale; SD, standard deviation.

Table 2 Multiple linear regression analysis

\begin{tabular}{|c|c|c|c|c|c|}
\hline & \multicolumn{2}{|c|}{$\begin{array}{l}\text { Not standardized } \\
\text { coefficients }\end{array}$} & \multirow{2}{*}{$\begin{array}{l}\text { Standardized } \\
\text { coefficients } \\
\beta\end{array}$} & \multirow[t]{2}{*}{$t$} & \multirow[t]{2}{*}{ Significance } \\
\hline & $\beta$ & SD error & & & \\
\hline Constant & 38.554 & 4.539 & & 8.493 & 0.000 \\
\hline Physical burden & 0.666 & 0.189 & 0.320 & 3.529 & 0.001 \\
\hline Developmental burden & 0.712 & 0.170 & 0.373 & 4.181 & $<0.001$ \\
\hline Socioeconomic status & -4.282 & 1.370 & -0.170 & -3.126 & 0.002 \\
\hline Urbanicity & 3.070 & 1.209 & 0.130 & 2.539 & 0.012 \\
\hline Age & 2.132 & 1.210 & 0.095 & $\mathrm{I} .762$ & 0.080 \\
\hline
\end{tabular}

Note: Dependent variable: SDS score.

Abbreviations: SDS, Self-Rating Depression Scale; SD, standard deviation. 
the needs of elderly people who are no longer self-sufficient. Over half the people examined in our study were close relatives of the patients (either son or daughter). As outlined in other studies, caregivers are often wives/husbands, sons, or daughters who have chosen to take care of the patient at their own homes, dedicating at least three quarters of their day to the patient. This period of time tends to increase in proportion to the advancement of the illness. ${ }^{23}$

\section{Burden and other factors}

Present data have shown that higher physical and developmental burdens, lower socioeconomic status, advanced age, and higher degree of urbanicity predict more severe depressive symptoms. Poor perceived state of health and quality of life are associated with anxious and depressive symptoms. $^{20}$

Close contact with a patient with dementia results in higher developmental and physical burdens for caregivers when compared with those who do not cohabit with the patient. On the other hand, a patient's functional impairment is more relevant than cognitive--behavioral alterations for the burden of the caregiver. ${ }^{24}$

With regard to the developmental burden, some studies have indicated that social isolation, among the factors, causes more impairment to caregivers' mental and physical well-being. ${ }^{25}$ Even at mild and moderate levels of dementia, caregivers begin to feel the repercussions that their family member's illness will have on their social life, desires, and expectations. Caregivers' uneasiness increases as patients' conditions worsen, adding to their increasing cognitive problems, the onset of behavioral symptoms, and the consequent reduction of independence in daily life; higher levels of anxiety are present among caregivers of patients with a long-lasting illness. ${ }^{26}$

As previously described, sociodemographic characteristics of caregivers are related to depressive symptomatology. In fact, many of them (eg, sex, socio-environmental and economic conditions, aspects of personality, and coping strategies) influence the caregiver's experience..$^{27,28}$

Truzzi et $\mathrm{al}^{4}$ demonstrated in a sample of 145 caregivers of patients with dementia that an elevated level of emotional impairment leads to depressive symptomatology and demoralization. ${ }^{29,30}$ Accordingly in our sample, approximately half of the caregivers showed at least mildly severe depressive symptoms.

Another study that analyzed 170 caregivers married to patients with dementia showed that wives had more severe depressive symptomatology than husbands; ${ }^{31}$ in fact, depression is two or three times more common among females. Nevertheless, our data did not show any difference either in the frequency or in the severity of depressive symptoms between the sexes. However, our results do support that low socioeconomic status is a risk factor for depression among caregivers. Another study found a threefold increased risk for experiencing high burden among caregivers of patients living in southern Italy; authors explained this result through a socioeconomic reasoning. ${ }^{32}$

\section{Limitations}

The study was limited by the fact that the evaluations were carried out just in one center, although it is the center of patient referrals in a consumer catchment area of about 150,000 inhabitants. Nevertheless, the results represent the real world of a poor region in southern Italy, where patients with dementia and their families find little support to cope with the illness. The patients were only given the Clinical Dementia Rating scale to assess the severity of their condition; other clinical and psychopathological measures might be helpful to further deepen the relationship of a patient's psychopathology and severity of dementia with the caregiver's burden.

\section{Conclusion}

Our study confirms both the presence of depressive symptoms in a high percentage of caregivers of patients with dementia and the association of depression with higher burden. Additionally, this study demonstrates that depressive symptoms in caregivers of patients with dementia are mainly associated with sociodemographic variables, such as advanced age, low socioeconomic status, greater urbanicity, and, to a lesser degree, physical and developmental burdens.

The need for preventive support and instructive programs to help reduce the burden for caregivers of patients with dementia is the main practical implication of these results. Such interventions could help to improve their emotional state and prevent the onset of depressive symptoms.

\section{Acknowledgments}

The authors thank Mrs T Gentile for her aid in data collection.

\section{Disclosure}

The authors report no conflicts of interest in this work.

\section{References}

1. Prince M, Bryce R, Albanese E, Wimo A, Ribeiro W, Ferri CP. The global prevalence of dementia: a systematic review and metaanalysis. Alzheimers Dement. 2013;9(1):63-75.

2. Cole JC, Ito D, Chen YJ, Cheng R, Bolognese J, Li-McLeod J. Impact of Alzheimer's disease on caregiver questionnaire: internal consistency, convergent validity, and test-retest reliability of a new measure for assessing caregiver burden. Health Qual Life Outcomes. 2014;12(1):114. 
3. Peña-Longobardo LM, Oliva-Moreno J. Caregiver burden in Alzheimer's disease patients in Spain. J Alzheimers Disease. 2015;43(4): 1293-1302.

4. Truzzi A, Valente L, Ulstein I, Engelhardt E, Laks J, Engedal K. Burnout in familial caregivers of patients with dementia. Revista Brasileira de Psiquiatria. 2012;34:405-412.

5. Ostwald SK. Caregiver exhaustion: caring for the hidden patients. $A d v$ Pract Nurs Q. 1997;3:29-35.

6. Roche V. The hidden patient: addressing the caregiver. Am J Med Sci. 2009;337(3):199-204.

7. Barr C, Riolacci-Dhoyen N, Galbraith M, Leperre-Desplanques A; ALCOVE Group. Sharing knowledge to advance healthcare policies in Europe for people living with dementia and their carers: the ALCOVE project. Arch Public Health. 2012;70(1):21.

8. Ferrara M, Langiano E, Di Brango T, De Vito E, Di Cioccio L, Bauco C. Prevalence of stress, anxiety and depression in with Alzheimer caregivers. Health Qual Life Outcomes. 2008;6:93.

9. Brodaty H, Donkin M. Family caregivers of people with dementia. Dialogues Clin Neurosci. 2009;11:217-228.

10. Mausbach BT, Patterson TL, Rabinowitz YG, Grant I, Schulz R. Depression and distress predict time to cardiovascular disease in dementia caregivers. Health Psychol. 2007;26:539-544.

11. Robison J, Fortinsky R, Kleppinger A, Shugrue N, Porter M. A broader view of family caregiving: effects of caregiving and caregiver conditions on depressive symptoms, health, work, and social isolation. $J$ Gerontol B Psychol Sci Soc Sci. 2009;64(6):788-798.

12. Hughes CP, Berg L, Danziger WL, Coben LA, Martin RL. A new clinical scale for the staging of dementia. Br J Psychiatry. 1982;140: $566-572$.

13. Novak M, Guest C. Application of a multidimensional caregiver burden inventory. Gerontologist. 1989;29:798-803.

14. Marvardi M, Mattioli P, Spazzafumo L, et al; Study Group on Brain Aging, Italian Society of Gerontology and Geriatrics. The Caregiver Burden Inventory in evaluating the burden of caregivers of elderly demented patients: results from a multicenter study. Aging Clin Exp Res. 2005;17:46-53.

15. Health Quality Ontario. Caregiver- and patient-directed interventions for dementia: an evidence-based analysis. Ont Health Technol Assess Ser. 2008;8(4):1-98.

16. Zung WW, Richards CB, Short MJ. Self-rating depression scale in an outpatient clinic. Further validation of the SDS. Arch Gen Psychiatry. 1965;13(6):508-515.

17. Cohen J. Statistical Power Analysis for the Behavioral Sciences. 2nd ed. Hillsdale: Lawrence Erlbaum Associates Inc.; 1988.

18. Balducci C, Mnich E, McKee KJ, et al. Negative impact and positive value in caregiving: validation of the COPE index in a six-country sample of carers Gerontologist. 2008;48(3):276-286. doi: 10.1093/ geront/48.3.276.
19. Hatch DJ, Dehart WB, Norton MC. Subjective stressors moderate effectiveness of a multi-component, multi-site intervention on caregiver depression and burden. Int J Geriatr Psychiatry. 2013;29:406-413.

20. Delgado Parada E, Suárez Alvarez O, de Dios Del Valle R, et al. Characteristics and factors associated with dementia caregivers' burden. Semergen/Sociedad Espanola de Medicina Rural Y Generalista. 2014;40(2):57-64.

21. Simpson C, Carter P. Short-term changes in sleep, mastery and stress: impacts on depression and health in dementia caregivers. Geriatr Nurs. 2013;34:509-516.

22. Fauth EB, Gibbons A. Which behavioral and psychological symptoms of dementia are the most problematic? Variability by prevalence, intensity, distress ratings, and associations with caregiver depressive symptoms. Int J Geriatr Psychiatry. 2014;29:263-271.

23. Aguglia E, Onor ML, Trevisiol M, Negro C, Saina M, Maso E. Stress in the caregivers of Alzheimer's patients: an experimental investigation in Italy. Am J of Alzheimers Dis Other Demen. 2004;19:248-252.

24. Raccichini A, Castellani S, Civerchia P, Fioravanti P, Scarpino O. The caregiver's burden of Alzheimer patients: differences between live-in and non-live-in. Am J Alzheimer's Dis Other Demen. 2009; 24:377-383.

25. Tognetti A. Le problematiche del caregiver [Caregiver: problems in the care]. Giornale di Gerontologia. 2004;54:505-510.

26. Passoni S, Mazzà M, Zanardi G, Bottini G. Levels of burden of Alzheimer disease caregivers. Giornale Italiano Di Medicina Del Lavoro Ed Ergonomia. 2010;32(3 suppl B):B37-B42.

27. Etters L, Goodall D, Harrison BE. Caregiver burden among dementia patient caregivers: a review of the literature. J Am Acad Nurse Pract. 2008;20:423-428.

28. Papastavrou E, Tsangari H, Karayiannis G, Papacostas S, Efstathiou G, Sourtzi P. Caring and coping: the dementia caregivers. Aging Ment Health. 2011;15:702-711.

29. Yilmaz A, Turan E, Gundogar D. Predictors of burnout in the family caregivers of Alzheimer's disease: evidence from Turkey. Australasian J Aging. 2009;28:16-21.

30. García-Alberca JM, Lara JP, Berthier ML. Anxiety and depression in caregivers are associated with patient and caregiver characteristics in Alzheimer's disease. Int J Psychiatry Med. 2011;41:57-69.

31. Välimäki TH, Vehviläinen-Julkunen KM, Pietilä A-MK, Pirttilä TA. Caregiver depression is associated with a low sense of coherence and health-related quality of life. Aging Ment Health. 2009;13: 799-807.

32. Rinaldi P, Spazzafumo L, Mastriforti R, et al. Predictors of high level of burden and distress in caregivers of demented patients: results of an Italian multicenter study. Int $J$ Geriatr Psychiatry. 2005;20: $168-174$.
Clinical Interventions in Aging

\section{Publish your work in this journal}

Clinical Interventions in Aging is an international, peer-reviewed journal focusing on evidence-based reports on the value or lack thereof of treatments intended to prevent or delay the onset of maladaptive correlates of aging in human beings. This journal is indexed on PubMed Central, MedLine,

\section{Dovepress}

CAS, Scopus and the Elsevier Bibliographic databases. The manuscript management system is completely online and includes a very quick and fair peer-review system, which is all easy to use. Visit http://www.dovepress. com/testimonials.php to read real quotes from published authors. 